\title{
Is Lymphostasis an Aggravant of Lipedema?
}

\author{
Maria de Fátima Guerreiro Godoy ${ }^{a}$ Edivandra Buzato ${ }^{b}$ \\ Patricia Amador Franco Brigidio ${ }^{a}$ \\ José Maria Pereira de Godoy ${ }^{c}$ \\ ${ }^{a}$ Faculty of Medicine of São José do Rio Preto (FAMERP) and Clínica Godoy, \\ ${ }^{b}$ Clínica Godoy, and 'Department of Cardiology and Cardiovascular Surgery, \\ Faculty of Medicine of São José do Rio Preto (FAMERP) and CNPq (National \\ Council for Research and Development), São Jose do Rio Preto, Brazil
}

\section{Key Words}

Lipedema $\cdot$ Edema outcome $\cdot$ Lymphedema

\begin{abstract}
A 54-year-old female patient reported that a characteristic of her family was 'fat legs' with postural edema since adolescence. Over the years the patient had been gaining weight with an increase in fatty tissue in the legs and arms. At the age of 24 years she started taking oral contraceptives and noted worse swelling and pain in the lower limbs. She was advised to suspend the use of the contraceptives and to start using a transdermal lymphatic system drug and physical exercise which partially improved the symptoms. Three years ago she noted that the swelling was increasing without improvement and sought a physician who raised the hypothesis of lymphedema and referred her to a specialized center. Lipedema and lymphedema was diagnosed in the physical examination. A 3-day intensive treatment program ( $8 \mathrm{~h}$ daily) was started for lymphedema which included manual and mechanical lymph drainage associated with short-strech $(<50 \mathrm{~mm} \mathrm{Hg}$ ) compression stockings custom made using a cotton-polyester fabric. Volumetry and perimetry were performed before starting and after the treatment and the legs were photographed. Volumetric and perimetric reductions were obtained suggesting the involvement of regional cutaneous lymphostasis in this disease.
\end{abstract}

\section{Introduction}

Lipedema was first described in 1940 by Allen and Hines, when it was defined as an abnormal deposition of adipose tissue in the lower limbs, without involvement of the feet, which usually affects women with a family history of the disease [1]. The characteristics of lipedema are an excessive deposit of fat in the lower limbs with the

José Maria Pereira de Godoy, MD, Avenida Constituição 1306

PhD São Jose do Rio Preto, SP 15025-120 (Brazil)

E-Mail godoyjmp@riopreto.com.br 
legs being classically described as having an 'Egyptian column' shape, presence of edema, skin hypothermia, changes in plantar support and a negative Stemmer sign $[2$, 3]. The disease naturally progresses and is usually associated with pain. It affects women more often than men with the initial diagnosis usually being made at puberty; often the disease is aggravated by pregnancy and late-onset cases can occur during menopause [3, 4]. Histological analysis of the tissue shows proliferation of progenitor cells derived from adipose tissue and necrosing adipocytes. It is caused by an increase in adipogenesis leading to necrosis of adipocytes and hypoxia [5]. Studies evaluating changes in lipedema showed that in lipo-lymphedema the lymphatic vessels are dilated and with obstructive characteristics and dermal reflux and in lipedema they are dilated but without signs of reflux [6]. The objective of this study is to demonstrate the reduction in the leg volumes (edema) in patients with lipo-lymphedema using manual and mechanical lymph drainage associated with short-strech compression stockings.

\section{Case Report}

A 54-year-old female patient reported that a characteristic of her family was 'fat legs' with postural edema since adolescence. Over the years the patient had been gaining weight with an increase in fatty tissue in the legs and arms. At the age of 24 years she started taking oral contraceptives and noted worse swelling and pain in the lower limbs. She was advised to suspend the use of the contraceptives and to start using a transdermal lymphatic system drug (topical) and to do physical exercise which partially improved the symptoms. Three years ago she noted that the swelling was increasing without improvement at rest and sought a physician who raised the hypothesis of lymphedema and referred her to a specialized center. Lipedema and lymphedema (lipo-lymphedema) were diagnosed in the physical examination, lymphedema was grade I. A three-day intensive treatment program ( $8 \mathrm{~h}$ daily) was started for lymphedema which included manual and mechanical lymph drainage associated with short-strech (<50 mm Hg) compression stockings custom made using a cotton-polyester fabric. Volumetry and perimetry were performed before starting and after the treatment and the legs were photographed (fig. 1a-c). After about $72 \mathrm{~h}$ of treatment over three days, there was volumetric reduction of more than $400 \mathrm{ml}$ below the right knee with the greatest perimetric reductions being around $5 \mathrm{~cm}$ both above and below the knees (table 1 , table 2).

\section{Discussion}

The current study reports on perimetric and volumetric reductions of the legs of a lipedema patient. The results of the intensive lymph drainage employed in this case suggest that there is pathophysiological involvement of this system in the increased leg volume. However, the characteristic of these patients is an accumulation in fat in the extremities.

With the passage of time, the main physiopathological change is necrosis of adipocytes which leads to cutaneous nodules $[4,5]$. However, changes in the lymphatic system showed that there was dilatation of the lymphatic collectors [6], which is suggestive of lymphatic stasis [7]. In addition, obesity is common in individuals where the accumulation of fatty tissue occurs mainly in the legs. Thus, changes in the lymphatic system may lead to increases in the volume of the legs. In this case the therapeutic approach led to reductions in volume confirming that the lymphatic system is responsible for this increase in volume. 
These patients may benefit from reduced leg size, but will continue with the characteristics of lipedema as the accumulation of adipose tissue is a characteristic of this disease. Hence, the only possible conduct is a physiopathological intervention with lymph drainage and weight loss.

Studies in the literature using pressure therapy showed reductions in leg size also suggesting the involvement of the lymphatic system [7]. The hypothesis that the lymphatic system is involved in lipedema seems to be related to cutaneous lymphostasis, where an obstructive pattern is not usually detected. Other interventions, such as liposculpture, do not interfere in the pathophysiology but in the shape of the limb and the removal of fatty tissue.

The present study supports the idea that this therapeutic approach interferes in the physiopathology, thus aggravating this physiological condition (lipedema).

\section{Conclusion}

Stimulation of the lymphatic system can be used to reduce leg volumes in patients with lipedema, thus suggesting the regional involvement of cutaneous lymphostasis in this disease.

Table 1. Volume of lower legs below the knee before and after treatment

\begin{tabular}{llllc}
\hline & \multicolumn{5}{l}{ Volumetry, ml } & & \\
\cline { 2 - 5 } & initial evaluation & final evaluation (after 3 days) & difference, ml & difference, \% \\
\hline Right leg & 3,928 & 3,513 & -415 & 10.60 \\
Left leg & 3,965 & 3,696 & -269 & 6.78 \\
\hline
\end{tabular}


Table 2. Perimetric size of legs before and after treatment

\begin{tabular}{|c|c|c|c|c|c|c|}
\hline \multirow[t]{2}{*}{ Site } & \multicolumn{2}{|c|}{ Initial evaluation, $\mathrm{cm}$} & \multicolumn{4}{|c|}{ Final evaluation (after 3 days), cm } \\
\hline & right & left & right & left & diff. right & diff. left \\
\hline Knee & 38 & 37.8 & 37.2 & 36.8 & -0.8 & -1 \\
\hline $5 \mathrm{~cm}$ above & 44.5 & 44 & 42 & 41.3 & -2.5 & -2.7 \\
\hline $10 \mathrm{~cm}$ above & 46.5 & 46.5 & 44.4 & 44.2 & -2.1 & -2.3 \\
\hline $15 \mathrm{~cm}$ above & 52 & 51.5 & 47.6 & 47 & -4.4 & -4.5 \\
\hline $20 \mathrm{~cm}$ above & 55 & 55 & 52.4 & 51.8 & -2.6 & -3.2 \\
\hline $25 \mathrm{~cm}$ above & 60 & 62 & 57.5 & 58.8 & -2.5 & -3.2 \\
\hline $30 \mathrm{~cm}$ above & 63 & 64.5 & 60.5 & 59.6 & -2.5 & -4.9 \\
\hline $35 \mathrm{~cm}$ above & 64 & 66 & 61.5 & 61.3 & -2.5 & -4.7 \\
\hline $5 \mathrm{~cm}$ below & 39 & 40 & 37 & 36.5 & -2 & -3.5 \\
\hline $10 \mathrm{~cm}$ below & 41 & 42 & 39.5 & 39 & -1.5 & -3 \\
\hline $15 \mathrm{~cm}$ below & 41.6 & 42.2 & 38.5 & 38.4 & -3.1 & -3.8 \\
\hline $20 \mathrm{~cm}$ below & 40 & 40 & 35.8 & 34.5 & -4.2 & -5.5 \\
\hline $25 \mathrm{~cm}$ below & 37 & 37 & 35 & 34.8 & -2 & -2.2 \\
\hline $30 \mathrm{~cm}$ below & 32 & 32 & 31.2 & 30.5 & -0.8 & -1.5 \\
\hline $35 \mathrm{~cm}$ below & 27 & 26.9 & 27 & 26 & 0 & -0.9 \\
\hline \multirow[t]{3}{*}{ Ankle } & 27 & 27.5 & 25.5 & 25.8 & -1.5 & -1.7 \\
\hline & & & & median & -2.3 & -3.1 \\
\hline & & & & mean & -2.1875 & -3.0375 \\
\hline
\end{tabular}
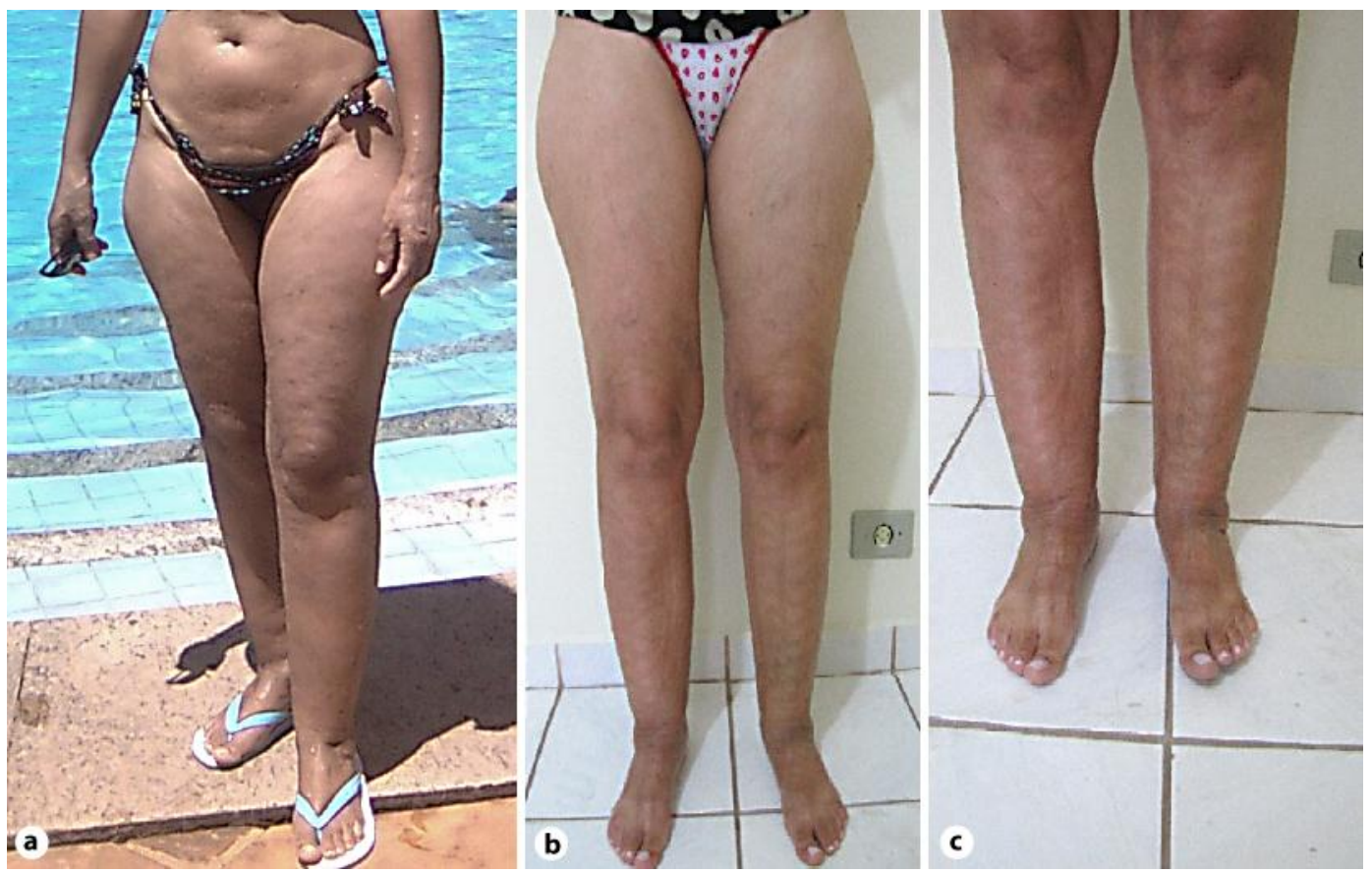

Fig. 1. Appearance of the legs before (a; image courtesy of the patient) and after treatment (b, c). 


\section{References}

1 Allen EV, Hines EA: Lipedema of the legs: a syndrome characterized by fat legs and orthostatic edema. Mayo Clin Proc 1940;15:184-187.

-2 Langendoen SI, Habbema L, Nijsten TEC, Neumann HAM: Lipoedema: from clinical presentation to therapy. A review of the literature. Br J Dermatol 2009;161:980-986.

-3 Wagner S: Lymphedema and lipedema - an overview of conservative treatment. Vasa 2011;40:271-279.

4 Pereira De Godoy JM, De Moura Álvares R, Simon Torati JL, De Fátima Guerreiro Godoy M: Clinical aspects of advanced stage lipo-lymphedema: case report. G Ital Dermatol Venereol 2010;145:547-549.

$\checkmark 5$ Suga H, Araki J, Aoi N, Higashino T, Yoshimura K: Adipose tissue remodeling in lipedema: adipocyte death and concurrent regeneration. J Cutan Pathol 2009;36:1293-1298.

6 Lohrmann C, Foeldi E, Langer M: MR imaging of the lymphatic system in patients with lipedema and lipo-lymphedema. Microvasc Res 2009;77:335-339.

7 Szolnoky G, Borsos B, Bársony K, Balogh M, Kemény L: Complete decongestive physiotherapy with and without pneumatic compression for treatment of lipedema: a pilot study. Lymphology 2008;41:40-44. 